\title{
Ultrastructural X-ray scattering studies of tropical and temperate hardwoods used as tonewoods
}

\author{
Mira Viljanen ${ }^{1, *}$, Patrik Ahvenainen ${ }^{1}$, Paavo Penttilä2,3, Hanna Help ${ }^{1}$, and \\ Kirsi Svedström ${ }^{1}$ \\ ${ }^{1}$ Department of Physics, University of Helsinki, P.O.B. 64, ooo14 Helsinki, Finland \\ ${ }^{2}$ Department of Bioproducts and Biosystems, Aalto University, P.O.B. 1630o, ooo76 Espoo, Finland \\ 3Large-Scale Structures Group, Institut Laue-Langevin, 71 avenue des Martyrs, F-38042 Grenoble, France \\ *Corresponding author; email: mira.viljanen@helsinki.fi \\ Accepted for publication: 2 April 2020
}

\begin{abstract}
The structure of hardwoods representing eight tropical and five temperate species was characterized from the atomistic level up to the cellular level using X-ray scattering, X-ray microtomography and light microscopy. The species were chosen for this study based on their popularity as tonewoods. The ultrastructure of wood cell walls, including crystallite size, orientation and close-range order of cellulose microfibrils were determined by small- and wide-angle X-ray scattering (SAXS, WAXS). The SAXS patterns were interpreted by using an analytical model of cylinders packed in a hexagonal close-range order with paracrystalline distortion. The values for the cylinder diameters given by this model were compared to the average crystallite widths obtained by WAXS using the Scherrer equation. In six out of 26 samples, all of these representing tropical species used especially in fretboard parts of electric guitars, large differences between these two sizes were obtained. The WAXS and microscopy results of these samples corresponded to tension wood structures. These comparisons and interpretations of SAXS results have not been previously presented for any tropical hardwoods, especially related to those containing tension wood tissue. The importance of the ultrastructural characterization was highlighted in this study in the case of tropical hardwood samples.
\end{abstract}

Keywords: Tension wood; wood nanostructure; small-angle X-ray scattering; wideangle X-ray scattering; cellulose crystallites. 


\section{INTRODUCTION}

The demand for forest biomass is growing annually, increasing the demand for both temperate and tropical forest resources and resulting in more aggressive logging in all forestry regions. Especially in the Asian market, the need for tropical hardwood timber is increasing (Shearman et al. 2012), which has caused some commonly used tree species (e.g. mahogany, ebony, rosewoods) to become vulnerable and even critically endangered (IUCN Red List (IUCN 2018)). The deforestation in tropical regions does not only concern the biodiversity but also has a negative impact on global climate and carbon sinks, thus strengthening the effect of climate change (Canadell \& Raupach 2008; Chow et al. 2013). Therefore, finding wood species with the same or similar properties matching the currently overharvested tropical species is essential. However, the structural properties of tropical hardwoods are far less characterized than the temperate zone species. Thus, structural studies on them are needed.

One of the use cases of tropical hardwoods is tonewood, i.e., the wood used in the parts of musical instruments. In this study, 8 tropical hardwood species and 5 temperate hardwood species were chosen as these species are among the most common wood species used especially as parts in electrical guitars (Ahvenainen 2019). The wood used in electric guitars can be classified into three classes based on how they are used in the guitar (Ahvenainen 2019). While the lowest-density class used in the guitar body only (marked as class 1 in this study) is quite often from a sustainable source, the medium density (class 2) and high-density class (class 3 ) woods used also in the neck and fretboard typically consist largely of endangered or threatened species. Many acoustical properties of wood depend on the specific gravity and the specific elastic modulus, though the two parameters are also correlated (Ahvenainen, 2019). Non-threatened but less studied and less used woods have the potential to be used as more environmentally friendly alternatives to the traditional tonewoods.

On the ultrastructural scale of wood, cellulose is accumulated into microfibrils due to hydrogen bonding and Van der Waals forces between the single cellulose chains. These microfibrils are embedded in a lignin-hemicellulose matrix in the cell walls of wood cells. The properties of microfibrils, such as crystallinity, crystallite width and orientation (expressed as microfibril angle, MFA), have a significant impact on the mechanical properties of wood (de Borst et al. 2012; de Borst \& Bader 2014).

Reaction wood is a special type of tissue generated as a response to mechanical stresses caused by external stimuli, such as windy weather or tilted stem growth. Reaction wood in hardwood species is called tension wood (TW) and often consists of strictly oriented, highly crystalline cellulose compared to normal wood (NW) (Gardiner et al. 2014). The presence of reaction wood is commercially significant as its fibers can influence the chemical pulping parameters as well as the workability and stability of hard timber wood (Gardiner et al. 2014).

A typical anatomical sign of TW in temperate hardwoods is the presence of thick-walled fibers having a gelatinous (G-) layer, which consists of nearly pure cellulose (Clair et al. 2018). However, this property is different in the case of many tropical species. Clair et al. (2006) studied TW anatomy in 21 different tropical rain forest species, and according to 
their results, in over 1/3 of these species, the presence of TW could not be detected by the presence of thick-layered gelatinous fibers. Recently, Roussel and Clair (2015), showed that in one of these species (Simarouba amara), actually a thin G-layer is produced, but it is masked by a late lignification. Ruelle et al. (2006) characterized also further the anatomical details of all these 21 tropical species and showed that the anatomical differences of fibres and vessels between highly stressed wood (TW) and NW were highly variable and weak. They suggested that the proper structural definition of TW should be determined by the ultrastructural scale details.

X-ray scattering methods are excellent for the structural characterization of biological samples because they are noninvasive, i.e. the samples do not have to be chemically treated or sectioned. Wide-angle X-ray scattering (WAXS) reveals the structural information from the atomistic level up to the nm-level. Using WAXS, the amount of crystalline cellulose among the total weight of the sample, the width of cellulose crystallites and their orientation can be determined for the wood samples. Small-angle X-ray scattering (SAXS) gives information on the nanoscale $(2-100 \mathrm{~nm})$ structure of the sample: using SAXS, the size, and shape of the scattering particles and their close-range order can be analyzed. In this study, the SAXS patterns, measured from the wet wood samples, were analyzed using an analytical model (WoodSAS), recently developed for the analysis of small-angle scattering data from wood samples, in which cellulose microfibrils were modeled as infinite long cylinders with a paracrystalline hexagonal close-range order (Penttilä et al. 2019).

In this study, the crystallite size, orientation and close-range order of cellulose microfibrils in hardwood samples representing 8 chosen tropical species were studied using WAXS and SAXS methods and compared with corresponding results from samples representing 5 temperate hardwood species. The aim was to gain information on the nanoscale structure of tropical hardwood samples using the complementary results of WAXS and SAXS on crystalline parts of the elementary cellulose microfibrils. Additionally, for the samples which showed possible traces of reaction wood, the aim was to see if the SAXS results obtained by the used model differed systematically between normal and reaction wood samples. This study aims also to see if the wood ultrastructure and the tonewood classification would be connected in some novel ways. There are few previous X-ray scattering results for the tropical hardwoods, and no systematic SAXS-WAXS results comparison has previously been made for any tropical wood.

\section{MATERIALS AND METHODS}

A total of 13 different temperate and tropical hardwood species were chosen to be studied with wide-angle (WAXS) and small-angle (SAXS) X-ray scattering techniques. The samples were acquired as a part of the Tonewood project (Ahvenainen et al. 2017a) from wood suppliers in Finland and other European countries. The temperate hardwood samples were obtained as donations from Finnish guitar luthiers (Kauko Liikanen, Kari Nieminen) and bought from Finnish wood distributing companies (OP-Puu Oy, Virkkalan Jalopuu). The tropical hardwood samples were bought from companies specialized in distributing raw wood materials for luthiers (Maderas Barber S.L (Spain), Mad Inter (Spain) and Exotic Hardwoods UK (UK), Timberline (UK)). 
Table 1.

A list of studied species with scientific names, an average of the measured specific gravity values (SG exp.), literature-based botanical specific gravity (SG lit.) (Meier 2015) and tonewood class based on how they are or could be used in electric guitars (Ahvenainen 2019).

\begin{tabular}{llccc}
\hline Species & Scientific name & SG exp. & SG lit. & $\begin{array}{c}\text { Tonewood class } \\
\text { based on SG exp. }\end{array}$ \\
\hline Gaboon ebony & Diospyros crassiflora & $0.97 \pm 0.06$ & 0.82 & 3 \\
Indian rosewood & Dalbergia latifolia & $0.78 \pm 0.15$ & 0.7 & 3 \\
Wenge & Millettia laurentii & $0.73 \pm 0.12$ & 0.7 & 3 \\
Msasa & Brachystegia spiciformis & $0.72 \pm 0.16$ & $\mathrm{NA}$ & 3 \\
Purpleheart & Peltogyne spp. & $0.72 \pm 0.02$ & 0.76 & 3 \\
Bubinga & Guibourtia spp. & $0.71 \pm 0.01$ & 0.72 & 3 \\
Zebrawood & Microberlinia spp. & $0.58 \pm 0.02$ & 0.67 & $2-3$ \\
European ash & Fraxinus excelsior & $0.56 \pm 0.04$ & 0.49 & $2-3$ \\
Silver birch & Betula pendula & $0.49 \pm 0.01$ & 0.5 & 2 \\
English oak & Quercus robur & $0.48 \pm 0.03$ & 0.53 & 2 \\
Honduran mahogany & Swietenia macrophylla & $0.44 \pm 0.01$ & 0.52 & 2 \\
Sycamore maple & Acer pseudoplatanus & $0.44 \pm 0.04$ & 0.43 & 2 \\
European alder & Alnus glutinosa & $0.35 \pm 0.02$ & 0.38 & 1 \\
\hline
\end{tabular}

The high SG value measured for ebony is discussed in the text.

The list of the species studied is presented in Table 1. From each species, two samples of different origin were studied, and from each of these samples, two approximately $0.2 \times 0.2 \times$ $2 \mathrm{~cm}^{3}$ sample blocks were cut from the xylem part of the wood. Half of the samples were soaked in water for one week prior to the WAXS and SAXS measurements at the European Synchrotron Radiation Facility.

The specific gravity (SG) values of the samples were determined by using a method described in (Chave \& Sabatier 2006). The volume used in SG determination was measured from fully water-soaked samples and the oven-dried weight was acquired after the samples were dried at $100^{\circ} \mathrm{C}$ for $42 \mathrm{~h}$.

\section{$X$-ray scattering experiments at $E S R F$}

SAXS and WAXS experiments were conducted at the D2AM beamline of the European Synchrotron Radiation Facility (ESRF) using an X-ray energy of $16 \mathrm{keV}$ with two XPAD hybrid-pixel detectors, separately for SAXS and WAXS. The measurements were conducted using perpendicular transmission geometry. Wet samples of Rosewood, Mahogany, Ebony, Maple, Alder, Ash and Msasa were sealed in Kapton tape and measured using both SAXS with two different detector distances (corresponding to low- $q$ and high- $q$ SAXS ranges) and WAXS. The WAXS data was used to compute the average crystallite width and moisture content (MC) in these samples. The other samples were measured as wet only in the high- $q$ SAXS range. Besides, all the samples were measured dry in the high- $q$ SAXS range.

The low- $q$ SAXS region (0.006-0.13 $\AA^{-1}$ ) was measured with a $\mathrm{D}_{5}$ detector at a distance of $216 \mathrm{~cm}$ from the sample. The high- $q$ SAXS region (o.02-0.49 $\AA^{-1}$ ) was studied using the 
same $\mathrm{D}_{5}$ detector but placed at a distance of $5^{8} \mathrm{~cm}$ from the sample. The WAXS region (o.61-4.0 $\AA^{-1}$ ) was studied with a WOS detector at a distance of $13 \mathrm{~cm}$. Term WOS stands for WAXS Open for SAXS, allowing simultaneous WAXS and SAXS experiments (Chahine et al. 2019).

The samples were positioned with the longitudinal axis of wood fibers perpendicular to the X-ray beam and the radial direction parallel to the beam (annual rings perpendicular to the beam). In each measurement, the samples were scanned horizontally either with 6 points within a $1-\mathrm{mm}$ range or with 11 points within a 2-mm range, with an exposure time of $5^{-10}$ s per point.

\section{Complementary WAXS experiments at $U H$}

Besides the X-ray scattering experiments at ESRF, all the samples were measured as dry using WAXS at the X-ray Laboratory at the University of Helsinki (UH). The measurements were conducted using the perpendicular transmission geometry with the set up consisting of a conventional sealed X-ray tube with a Montel monochromator to select the $\mathrm{Cu} \mathrm{K}-\alpha$ wavelength and a Mar345 area detector. From these data, the average crystallite widths and MFAs were determined for all the samples.

\section{Tomography experiments at $U H$}

To illustrate the different cellular level structures, selected tropical wood samples (representing Ebony, Bubinga, Purpleheart and Zebrawood) were also 3D imaged using X-ray microtomography $(\mu \mathrm{CT})$ at the X-ray Micro-CT Laboratory at the University of Helsinki. The measurements were carried out using the GE Phoenix Nanotom setup described in (Ahvenainen et al. 2017b) with a voxel size of $5 \mu \mathrm{m}$.

\section{Data analysis}

In the preliminary processing of the data measured at ESRF, WAXS and SAXS data from different spots in a sample were averaged and normalized using the transmitted beam intensity. Background arising from the Kapton-tape (wet samples) and the air was subtracted. The SAXS data were integrated on 25-degree sectors around the maximum of the azimuthal profile after isotropic contribution (minimum of the azimuthal profile) subtraction, as detailed in (Penttilä et al. 2019). The WAXS data were integrated in a similar manner around the azimuthal maxima (without subtracting the isotropic background at this point).

The SAXS data was further analyzed with SasView software (Doucet et al. 2017) using the WoodSAS model developed by P.A Penttilä (Penttilä et al. 2019) based on the paracrystalline cylinder model (Hashimoto et al. 1994). The WoodSAS model can be downloaded as a plug-in model in SasView, and both the software and the model are freely distributed. The analytical analysis of SAXS patterns is based on the assumption of two phases (i.e. two different electron densities): (1) crystalline cellulose and (2) water background including water-infused lignin-hemicellulose matrix (Jakob et al. 1996; Leppänen et al. 2009). Wet wood can thus be modeled as a two-component system consisting of crystalline cellulose microfibrils in a water-hemicellulose-lignin matrix. The cellulose microfibrils were modeled as infinitely long cylinders with a Gaussian size distribution and having a hexagonal 
close-range ordering with a paracrystalline distortion. The model can be used to obtain the average diameter of the cylinders with Gaussian variation in addition to the average distances between the cylinders with the variation included in the paracrystal model (Penttilä et al. 2019). In addition to these terms, the WoodSAS model includes a Gaussian function centered at $q=0 \AA^{-1}$, which can describe the scattering from features other than the crystalline cellulose microfibrils, such as nano-sized pores.

From all the WAXS data (measured both at ESRF and UH), the 20o-reflection was analyzed to determine the crystallite width of the cellulose microfibrils.

A Gaussian curve fitting method, which took into account the amorphous (isotropic) background of the cell wall components and the water background (only in the case of the wet samples), was used to calculate the FWHM from the cellulose 200 peak and the Scherrer equation was used to compute the average widths of the crystallites (as presented in Leppänen et al. 2011). The instrumental broadening was estimated to be $0.43^{\circ}$ for the $\mathrm{UH}$ experiments and zero in the case of ESRF experiments.

It was also possible to obtain information on the moisture content (MC) using the WAXS patterns of wet samples measured at ESRF. It should be noted that the MC values are determined from samples with a preferred orientation, so the values are relative, i.e. they are only comparable between the samples included in this study.

From the WAXS patterns measured at $\mathrm{UH}$, the orientation of the cellulose microfibrils were analyzed from the azimuthal intensity of the 200 reflections. This was done using average microfibril angle determination computed by the fitting of two pairs of Gaussians and one Gaussian at angle $o$ (which takes into account the factor arising from the cell shape) in a similar way as in Sarén et al. (2004).

\section{Histochemical analysis}

The possible tension wood presence in some samples was further studied by histochemical analysis at the University of Helsinki, Institute of Biotechnology. The analysis was done on the sections cut from the same pieces which were measured at the ESRF by SAXS and WAXS. To minimize the sectioning damage to the samples, they were embedded in historesin. Before the embedding, the samples were dehydrated with a series of different ethyl alcohol- concentrations and placed in FAA (formalin-acetic-alcohol) solution (50\% ethyl alcohol, $5 \%$ glacial acetic acid, $10 \%$ formaldehyde (37-40\%), $35 \%$ distilled water). The embedded samples were further cut into $10 \mu \mathrm{m}$ thick slices using a microtome and placed onto microscope glass slides. Just before the imaging, the sample slices were stained with Alcian blue to quantify the different proportions of cellulose in the xylem tissue. The stained sample slices with reference pairs were imaged with a Leica DMLB250o optical microscope using an integrated camera.

\section{RESULTS AND DISCUSSION}

All the WAXS and SAXS results are given in Table 2. 
Table 2.

Average crystallite width and MFA (determined based on the cellulose 200 reflection in the WAXS patterns) and diameter of and distance between the cylinders (both given with fitted polydispersity in parentheses) based on the analysis of the SAXS patterns of wet samples.

\begin{tabular}{|c|c|c|c|c|c|}
\hline Sample & $\begin{array}{l}\text { Crystal width } \\
(\mathrm{nm}) \pm 0.2 \\
\mathrm{~nm}\end{array}$ & $<\mathrm{MFA}>\left(^{\circ}\right) \pm 1.0^{\circ}$ & $\begin{array}{c}\text { Cylinder } \\
\text { diameter } \\
(\mathrm{nm})\end{array}$ & $\begin{array}{l}\text { Distance } \\
(\mathrm{nm})\end{array}$ & MC $(\%) \pm 3 \%$-unit \\
\hline Ebony A & 2.9 & 8.5 & $2.4(0.5)$ & $2.7(1.3)$ & 32 \\
\hline Ebony B & 2.8 & 2.2 & $2.6(0.5)$ & $3.0(1.3)$ & 30 \\
\hline Rosewood A & $3.7(3.2)$ & 9.1 & $2.0(0.4)$ & $1.7(0.7)$ & 18 \\
\hline Rosewood B & $4.1(3.6)$ & 27 & $2.0(0.4)$ & $1.9(0.8)$ & 31 \\
\hline Wenge A & 4.7 & 6.2 & $2.5(0.4)$ & $2.5(1.0)$ & \\
\hline Wenge B & $3 \cdot 3$ & 4.9 & $2.6(0.4)$ & $2.7(1.1)$ & \\
\hline Msasa Mza A & $3 \cdot 9$ & 4.9 & $2.0(0.4)$ & $1.9(1.0)$ & 37 \\
\hline Msasa Mza B & 3.1 & $5 \cdot 5$ & $2.6(0.5)$ & $3.5(1.3)$ & 42 \\
\hline Purpleheart A & $3 \cdot 3$ & $3 \cdot 9$ & $2.0(0.4)$ & $1.8(0.7)$ & \\
\hline Purpleheart B & $3 \cdot 9$ & $3 \cdot 4$ & $2.3(0.5)$ & $2.6(1.2)$ & \\
\hline Bubinga A & $3 \cdot 3$ & 6.6 & $2.6(0.5)$ & $3.2(1.4)$ & \\
\hline Bubinga B & 4.1 & $5 \cdot 9$ & $2.0(0.3)$ & $2.3(0.7)$ & \\
\hline Zebrawood A & 3.2 & 5.1 & $2.6(0.5)$ & $3.5(1.6)$ & \\
\hline Zebrawood B & 3.2 & $5 \cdot 5$ & $2.6(0.4)$ & $3.0(1.3)$ & \\
\hline Ash A & 3 & 15 & $2.6(0.5)$ & $3.8(1.4)$ & 44 \\
\hline Ash B & $3 \cdot 3$ & 10 & $2.5(0.4)$ & $3.0(1.2)$ & 40 \\
\hline Birch A & 3 & 11 & $2.7(0.5)$ & $3.6(1.5)$ & \\
\hline Birch B & 3.1 & 12 & $2.6(0.5)$ & $3.3(1.5)$ & \\
\hline Oak A & 2.9 & $9 \cdot 5$ & $2.6(0.5)$ & $3.6(1.3)$ & \\
\hline Oak B & 3 & 6.6 & $2.6(0.5)$ & $3.7(1.2)$ & \\
\hline Mahogany A & 3 & 3 & $2.4(0.5)$ & $2.6(1.1)$ & 37 \\
\hline Mahogany B & 3 & 6.8 & $2.4(0.5)$ & $2.5(1.0)$ & 45 \\
\hline Maple A & 3 & 28 & $2.5(0.5)$ & $3.4(1.3)$ & 45 \\
\hline Maple B & 3 & 12 & $2.6(0.5)$ & $3.8(1.4)$ & 47 \\
\hline Alder A & 3.2 & $5 \cdot 4$ & $2.5(0.5)$ & $3 \cdot 3(1.3)$ & 47 \\
\hline Alder B & 3.1 & 2.7 & $2.6(0.5)$ & $3.5(1.4)$ & 46 \\
\hline
\end{tabular}

For the samples with an MC value, the crystallite width has been analyzed from the WAXS data measured from wet samples at ESRF and as for the rest of the samples, the crystallite width has been computed from the WAXS data measured at UH. For Rosewood samples, the value of crystallite width measured at UH has also been presented in brackets due to major divergence from the ESRF value.

\section{WAXS results}

Based on the WAXS results, most of the average crystallite widths of the tropical hardwood species of this study are generally the same as in the temperate hardwoods (2.8$3.3 \mathrm{~nm})$. Corresponding values for the crystallite width $(2.8-3.2 \mathrm{~nm})$ have also been obtained for common softwood species studied by WAXS: for spruce (Andersson et al. 2003; Leppänen et al. 2009; Fernandes et al. 2011; Penttilä etal. 2019), pine (Andersson et al. 2005), 


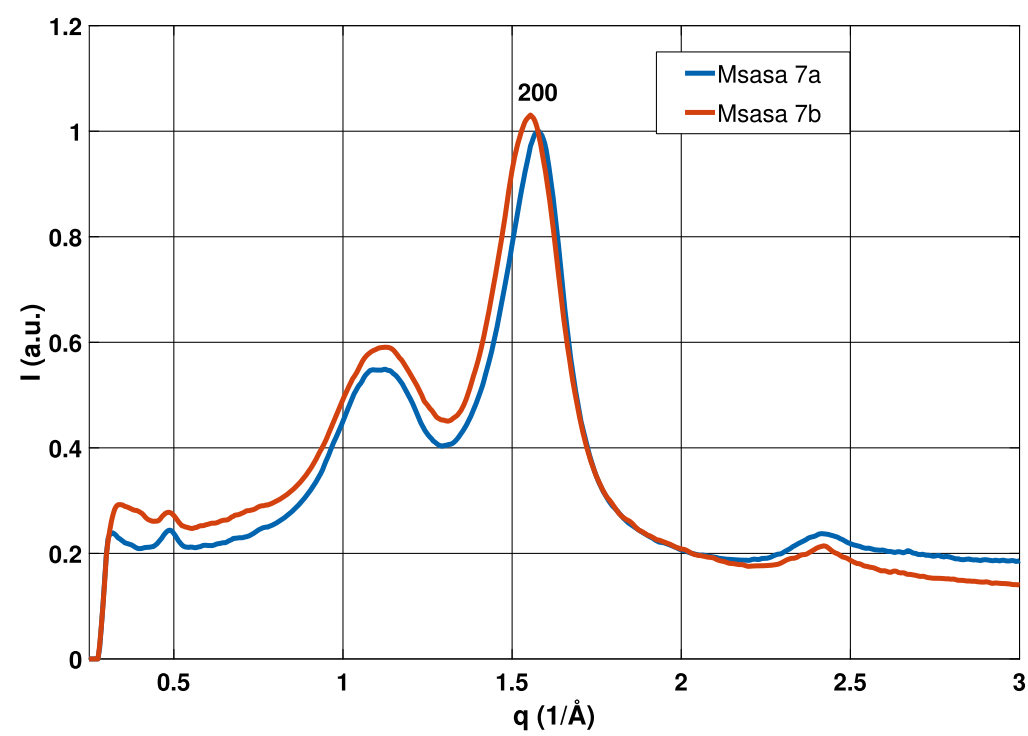

Figure 1. Comparison of Msasa A and B WAXS patterns. The sharper 200 peak indicates a larger cellulose crystallite width in the Msasa A sample, indicating a possible presence of tension wood.

Ginkgo (Andersson et al. 2015), juniper (Hänninen et al. 2012) and also for non-wood sample such as bamboo (Wang et al. 2012) and sunflower (Thomas et al. 2014).

Relatively large exceptions to this $3 \mathrm{~nm}$ width were found for some of the samples representing Rosewood, Wenge, Msasa, Purpleheart and Bubinga where the average cellulose crystallite width was determined to be significantly larger $(3 \cdot 7-4.7 \mathrm{~nm}$, the accuracy of the method being $0.2 \mathrm{~nm}$ ). The difference is shown in the WAXS intensity curves in the case of Msasa A and Msasa B samples, where sample A showed a larger crystallite width (Fig. 1). It can be observed, that there is a clear shift in the position of the cellulose 200 peak between the samples A and B. This confirms the crystallite width determination because a larger cellulose crystallite width is connected to a smaller lattice distance i.e. the larger cellulose crystallites are known to be more compact (Ioelovich \& Larina 1999; Newman et al. 2013).

One explanation for the larger crystallite width is the presence of tension wood in the samples. It has been detected in several previous X-ray diffraction studies, that the cellulose crystallite width in TW is similar to that observed in this study i.e. around 4 $-5 \mathrm{~nm}$ (Müller et al. 2006; Ruelle et al. 2007; Leppänen et al. 2011; Sawada et al. 2018). The more marked aggregation of cellulose crystallites has been suggested as an explanation for the larger widths in previous studies (Müller et al. 2006; Sawada et al. 2018), and the lower lignin content of TW has been considered as one of the factors behind this (Foston et al. 2011). It can also be noted that based on specific gravity all these samples represent class 3 tonewoods (see Table 1), i.e. the densest wood used for making the electric guitars.

Ruelle et al. (2007) studied the crystallite widths in three tropical rainforest hardwoods with TW occurrence and obtained an increasing relationship between larger crystallite size and the measured macroscopic strain in trees. The three species in their study were selected 
based on three different anatomical characteristics of TW: Eperua falcate having G-fibers, Laetia procera having multilayered TW fibres and Simarouba amara with the lack of any anatomical signs of TW. In all these three species, the relationship between the crystallite size and growth strain was the same, so their results highlight the importance of the determination of ultrastructural characteristics.

Small microfibril angles $\left(\leqslant 10^{\circ}\right)$ were detected throughout the sample series with only a few exceptions: for one of the Rosewood (B) and Maple (A) samples relatively large average MFAs $\left(>25^{\circ}\right)$ were obtained. These exceptions might be explained by natural, biological variation in the studied wood materials or by the density of rays in the measured spot/location. However, either the large MFA value or the small crystallite width determined by the data measured at UH for the Rosewood B sample do not correspond to TW (as all the other scattering results shown in Table 2). Here it should be noted that the WAXS measurement conducted at UH does not correspond exactly to the same macroscopic spot/location in the sample as the WAXS measurement at ESRF. Also, in the case of the two Purpleheart samples, where the SAXS results of the specimen were measured at ESRF and the WAXS results correspond to measurements conducted at UH, these show a discrepancy. These results reflect the important fact that the occurrence of TW tissues in these pieces of wood covers certain ranges, but not the whole macroscopic sample (Badia et al. 2006; Ghislain \& Clair 2017). However, all the other crystallite width results from the samples, determined either as wet at ESRF or as dry at UH were the same. It should also be emphasized that the MC differences do not explain the large differences detected in the crystallite widths. We have determined the moisture effect previously in hardwood and the largest observed effect of MC on the crystallite width determination (the FWHM of the 200 reflection determined in the fully wet vs. air-dried states) was less than $10 \%$ (Leppänen et al. 2011).

In the WAXS patterns of some tropical wood species (Ebony, Rosewood, Mahogany, Wenge and Zebrawood) relatively large crystallites of mineral extractives were present (Fig. A 1 in the Appendix). This has previously been observed also in the xylem of Diospyros kaki-species (belonging to the same genus as Ebony), studied with X-ray powder diffraction alongside other methods (including X-ray fluorescence, scanning and transmission electron microscopy) in (Tazaki et al. 2017). The study suggested that the most common elements and compounds are formed from $\mathrm{Ca}, \mathrm{Mg}, \mathrm{Si}, \mathrm{P}, \mathrm{S}, \mathrm{Cl}$ and $\mathrm{K}$, depending on the examined part of the tree.

The extractives (including the inorganic compounds) are also relevant when considering the density and specific gravity of different wood species. A relatively large value of SG compared to the literature one was obtained for ebony $(0.97 \pm 0.06)$ in Table 1 . The ebony samples studied had a very dark blackish color, indicating the presence of extractives in significant concentrations. This may also explain the large SG value obtained for ebony in this study.

\section{SAXS results}

The used SAXS model, WoodSAS, could be applied reliably for all the wet wood samples of this study. Examples of fits are presented in Figs 2 and 3. In the model it is assumed that 


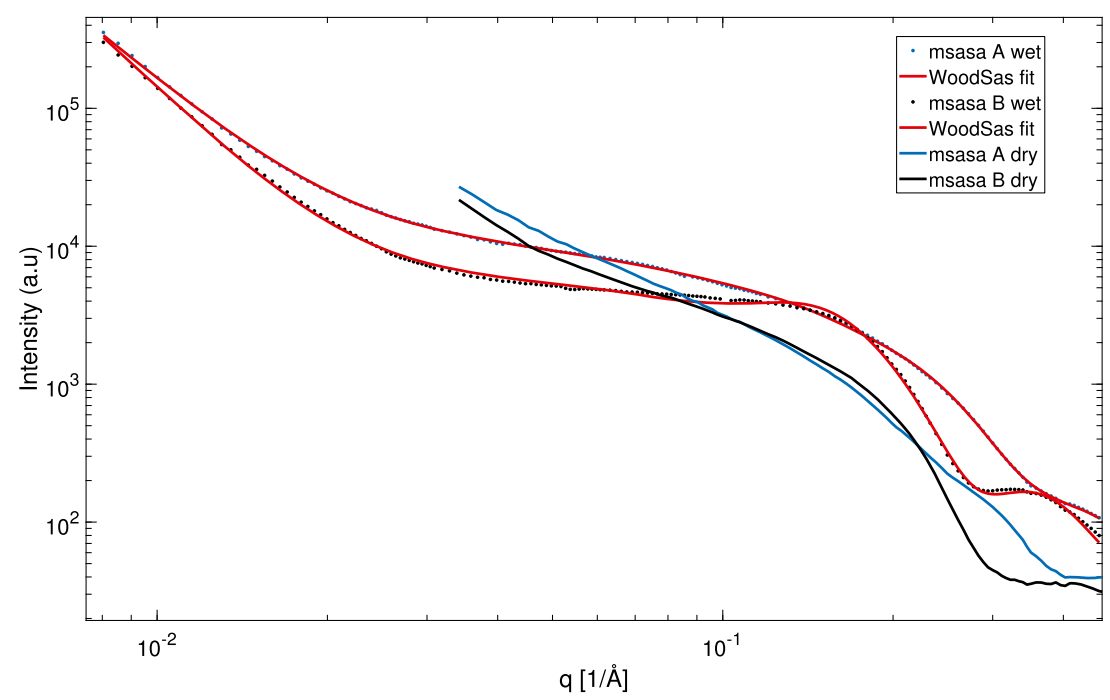

Figure 2. SAXS patterns and WoodSAS fits of Msasa samples. The samples were measured as wet using both a low q range (ranging into $0.0061 / \AA ̊$ at low $q$ ) and a high $q$ range. Here the results of these two ranges are combined for the wet samples. The figure shows also the limits of the two ranges used because the dry samples were measured only using the higher $q$ range. It can be observed that the low q range is dominated by the power-law behavior and that the SAXS fitting results on the cylinder diameters and packing are obtained from the $q$ range around $0.07-0.351 / \AA$.

wood can be considered to consist of different phases, corresponding to different electron densities, which are crystalline cellulose, amorphous matrix, and nanopores of cell walls. To take into account scattering from, e.g., pores, the WoodSAS model includes a Gaussian term. However, this Gaussian term could be omitted in the cases of all the wet temperate wood samples and also most of the wet tropical wood samples. This indicates that the twophase model describing crystalline cellulose microfibrils as cylinders in the water-infused amorphous matrix depicts very well the nanostructure of these samples.

Exceptions to this were the wet samples of Rosewood (both A and B), Msasa (A), Purpleheart (A) and Bubinga (B). The Gaussian term was included in the fitting of the SAXS patterns of these samples. These samples showed markedly different SAXS patterns corresponding to smaller cylinder diameters. In these same samples were observed higher cellulose crystallite widths determined by WAXS. Thus, one interpretation for these samples, reasserting the WAXS results, is that these samples include reaction wood, i.e., TW with gelatinous layers. This would also explain the larger role of the Gaussian term because this term could arise from the scattering from the nanosized pores of the G-layer. This interpretation and the related observations are strengthened by the results of beech TW measured by SAXS and small-angle neutron scattering (SANS) by Penttilä et al. (2020) and the results of poplar TW measured by SANS by Sawada et al. (2018).

The more porous G-layer structure compared to normal cell wall layers has been observed and analyzed by $\mathrm{N}_{2}$ adsorption measurements (Chang et al. 2009, 2015; Clair et al. 


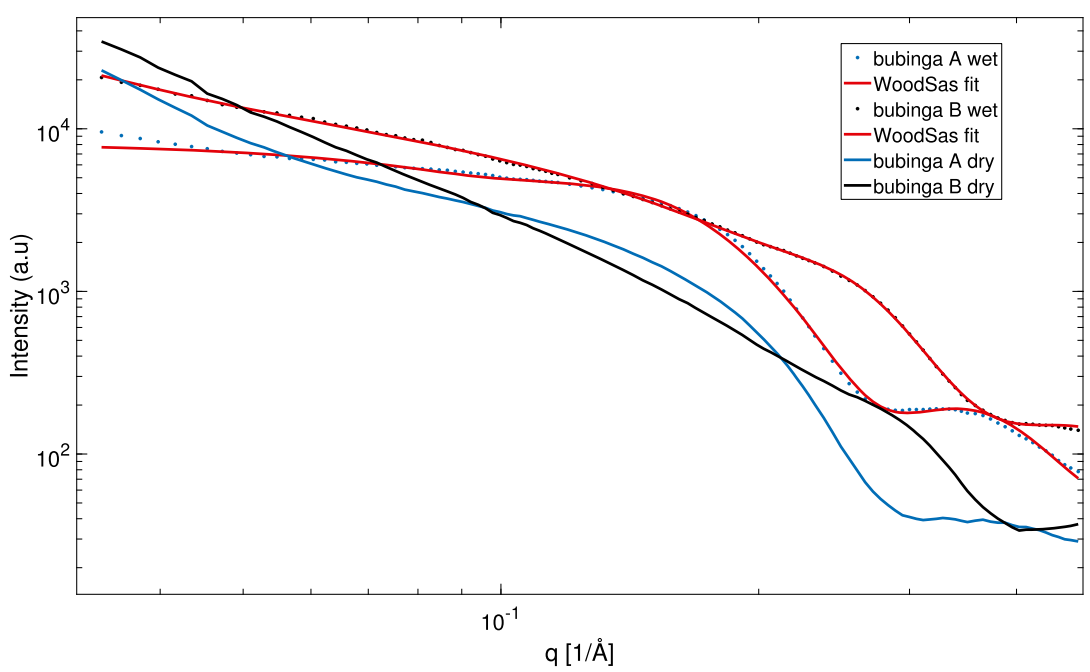

Figure 3. SAXS patterns and WoodSAS fits for the Bubinga samples (Bubinga A corresponding to normal wood and Bubinga B corresponding to possible TW).

2018). Based on the results on six tropical wood species, (Chang et al. 2009) showed that the porosity is highest for the species with TW with thick G-layer and determined the pore size distribution be located around $6-12 \mathrm{~nm}$. This size scale corresponds well to the $q$-range covered by the Gaussian term in the SAXS patterns of our study. Also Sawada et al. determined the mean size for nanopores in poplar TW to be $6 \mathrm{~nm}$ by particle size distribution analysis (Sawada et al. 2018).

Using the WAXS patterns measured at the ESRF, it was possible to determine the moisture content (MC) of the wet samples (Rosewood, Mahogany, Ebony, Msasa, Purpleheart, Maple and Oak) (Fig. 4). Based on the results, it could be noted that the water content was larger in the temperate samples compared to the tropical samples. The lowest water content was obtained for the rosewood samples and the highest water content was obtained for maple and alder. The SAXS results did not correlate with the MC values, so the differences between the sample water contents did not explain the differences between the SAXS results. Thus, it could be concluded that the SAXS results reflect the differences in the nanostructures of the samples.

The SAXS patterns of the dry samples of this study could not be analyzed reliably enough using the model, because the fittings depended highly on the values of starting parameters (i.e., were not stable). This can be explained by the fact that in the case of dry wood, the electron density difference between air-filled nanopores and wood cell wall materials is higher than the electron density difference between the matrix and the crystalline cellulose. Thus, in dry wood, the scattering pattern arising from the cellulose microfibrils is surpassed by the scattering of pore structures. So, all the SAXS results in Table 2 correspond to the results of wet samples. 


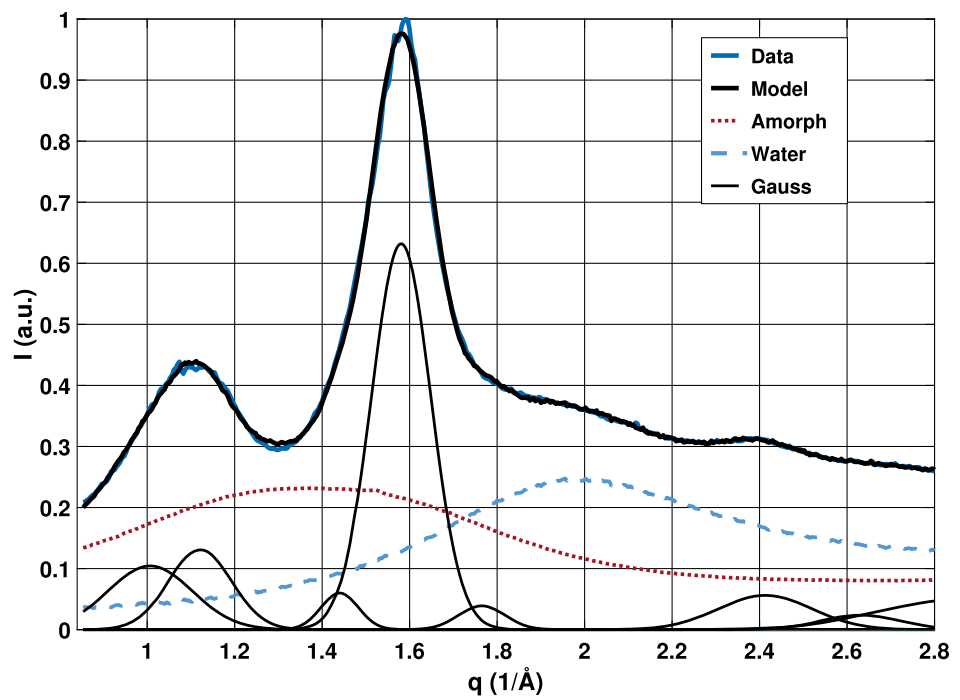

Figure 4. WAXS pattern fitting for Msasa A sample measured at ESRF. The WAXS curve was analyzed by a linear combination of measured water (blue dashed curve) and amorphous background (red dashed curve) besides the crystalline part as a sum of Gaussian functions (Gaussian peaks expressed as grey solid curves). The MC, in this case, was computed to be $37 \pm 3 \%$ based on the fit shown here.

Based on the SAXS fitting results, the distance between the cylinders (parameter "distance" in Table 2) is smaller i.e. the packing of the elementary cellulose microfibrils is denser, in the case of the tropical hardwoods (normal wood average being $3.0 \mathrm{~nm}$ excluding all the possible TW samples which showed even smaller values of distance) compared to the temperate hardwoods of this study (average being $3.5 \mathrm{~nm}$ ). Using SAXS, Penttilä $e t$ al. (2019) determined the interfibrillar distance for a wet sample of birch to be approximately $3.7 \mathrm{~nm}$, which corresponds well to the average value determined for temperate wood samples in our study. Interestingly, in the case of temperate softwoods, the distance was determined to be even larger: around $4 \mathrm{~nm}$ was obtained for wet spruce and pine (Penttilä $e t$ al. 2019).

In the case of possible TW samples (Rosewood A and B, Bubinga B, Msasa A and both Purplehearts A and B), the WoodSAS fits depended more on the initial values of the fits than in the case of other wet samples. Thus, the values given for the distances (parameter "distance" in Table 2) for these possible TW samples are not as reliable as for the wet normal wood samples. The distance values of the possible TW samples are so small that the interfibrillar distance matches the cylinder diameter values. This corresponds to the previous observations by, e.g., Sawada et al. (2018) that the coalescence of the elementary microfibrils is common in TW, which also explains the large crystallite widths by WAXS. It should be noted, that the WoodSAS fits for these TW samples could also be conducted using larger values of interfibrillar distance $(4-6 \mathrm{~nm})$ based on the values presented for beech TW by Penttilä et al. (2020). Based on the goodness of fit values, the fits were slightly better in the case of smaller interfibrillar distance values and thus they are given in Table 2. The 
main conclusion on the SAXS results of the possible TW samples of this study is that the peculiar shape of the SAXS curve distinguishes TW nanostructure from the normal wood nanostructure, but the quantitative values based on the used fits are not as reliable as in the case of wet normal wood samples.

\section{Comparison between WAXS and SAXS results of the cellulose microfibrils}

All the scattering results of this study on the cellulose microfibril structures reveal the question about the nature of the cellulose crystallites. Both SAXS and WAXS signal arises from the electron densities of the sample. In WAXS, the result is based on the approximations made in the Scherrer equation relying on diffraction from the lattice planes, whereas the SAXS result is based on the approximations in the analytical model of hexagonally packed cylinders. In this study, the WAXS (i.e., Scherrer) analysis gave larger values regarding the average cellulose crystallite widths than the SAXS analysis regarding the diameters of cylinders presenting the elementary cellulose microfibrils. A similar discrepancy has been detected also earlier (Jakob et al. 1995; Leppänen et al. 2009; Penttilä et al. 2019, 2020). The larger crystallite widths obtained by WAXS can be explained by the aggregation of the elementary cellulose microfibrils (Jarvis 2018). Thus, the smaller crystallite diameters observed by SAXS may correspond to the size of the elementary cellulose crystals, whereas the WAXS results correspond to an average crystallite size with a stronger contribution from the aggregates compared to SAXS. However, it should also be noted that the Scherrer equation gives the average minimum crystalline domain size, indicating that the obtained WAXS result is the lower limit of the average aggregate sizes.

Interestingly, in this study, the difference between WAXS and SAXS results was observed to be even greater in the case of the possible TW samples. The WAXS results gave larger crystallite sizes than in NW samples whereas the SAXS results for cylinder diameters gave even smaller values than in the case of NW samples. Thus, following the previous assumption, also in the case of TW samples, SAXS detects the individual, elementary crystalline microfibrils, whereas the WAXS result is weighted by the even larger aggregates of TW compared to NW. However, in the case of TW, it must also be noted that the SAXS analysis might be affected by the overlaying contribution of the scattering of nanopores.

\section{Microscopy and $\mu$ CT results}

Microscopy and staining experiments were conducted on Rosewood, Ebony and Msasa (both A and B) samples. It was observed, that the cell walls were relatively thick and rays were abundant in all the samples studied (Fig. $\mathrm{A}_{3}$ in the Appendix). Based on the microscopy images, there are detached, thick-walled, collapsed and thus highly nonsymmetric cells in Rosewood A and B and Msasa A samples. These characteristics can be indicative of TW cells (Claire et al. 2006).

However, the difference between possible TW and NW could not be revealed by staining between the studied samples. This might be explained by the high density of the studied woods, which could affect the contribution of stain.

Microtomography imaging was conducted on a single sample of each (Bubinga B and Purpleheart B) based on the WAXS and SAXS results indicating TW presence, and for two 
tropical wood samples of NW (Ebony and Zebrawood). With a $5 \mu \mathrm{m}$ voxel size, structural details of vessels and rays can be observed in the samples (Figs. A1 and A2 in the Appendix). In the earlier work of Brereton et al. (2015), the TW pattern in willow sapling phloem has been successfully imaged with $\mu \mathrm{CT}$ using a $9 \mu \mathrm{m}$ voxel size.

The inability to observe the details of TW xylem using $\mu \mathrm{CT}$ in the measured tropical wood samples can be explained by the greater density of the tropical hardwoods. Thus, possible TW tissues in tropical hardwoods cannot be tracked unambiguously using only imaging methods. This highlights the applicability of X-ray scattering techniques (WAXS, SAXS) to confirm the presence of TW.

\section{CONCLUSIONS}

The SAXS results showed that the packing density of the elementary cellulose microfibrils was greater in tropical hardwoods studied in this work compared to temperate hardwoods and the difference was even more significant compared to softwood results found in the literature.

For some specimens representing tropical species, larger cellulose crystallite widths were detected based on the WAXS data, indicating the possible presence of tension wood. The SAXS patterns of the same samples also showed features typical for TW as the scattering was presumably dominated by nanopores. In this study, a consistent difference between the average crystallite width obtained by WAXS and the cylinder diameter obtained by SAXS was observed and this difference was more significant in the case of the possible TW samples.

The ultrastructural characterization and identification of possible TW characteristics in the samples studied are important especially when the mechanical behavior of the samples is of interest, e.g., in the case of wood used as tonewoods. The results of this study suggest that the properties and characteristics of especially Msasa wood should be studied further considering its application possibilities.

\section{ACKNOWLEDGEMENTS}

K.S. and M.V. acknowledge the University of Helsinki (3-year research grant). Samples were obtained with funding from Kone Foundation. P.A. also thanks Kone Foundation for funding and Finnish luthiers Kauko Liikanen and Kari Nieminen; Atte Jussila from OP-Puu; and Dr. Tuula Jyske for assistance in acquiring samples during the project. P.P. thanks Emil Aaltonen Foundation and Academy of Finland (grant no. 315768) for funding. The SAXS and the wet-state WAXS experiments were performed on the French CRG beamline D2am at the ESRF (experiment 02-01-885), and Dr. Isabelle Morfin from CNRS/University of Grenoble Alpes, LIPhy, is thanked for providing assistance in using the beamline. The WOS detector at D2AM was funded by the French National Research Agency (ANR) under the "Investissements d'avenir" program (grant no. ANR-11-EQPX-oo1o). In addition, this work benefited from the use of the SasView application, originally developed under NSF award DMR-0520547. SasView contains code developed with funding from the European Union's Horizon 2020 research and innovation programme under the SINE2O2O project, grant agreement No 654000 . 


\section{REFERENCES}

Ahvenainen P, Viljanen M, Mäkinen H, Help H, Suhonen H, Huotari S. 2017a. Tonewood project — wood used in electric guitars. Available online at https://www.researchgate.net/publication/ 321805990_TONEWOOD_PROJECT_-_WOOD_USED_IN_ELECTRIC_GUITARS.

Ahvenainen P, Dixon PG, Kallonen A, Suhonen H, Gibson LJ, Svedström K. 2017b. Spatially-localized bench-top X-ray scattering reveals tissue-specific microfibril orientation in Moso bamboo. Plant Methods 13: 5. DOI: 10.1186/s13007-016-0155-1.

Ahvenainen P. 2019. Anatomy and mechanical properties of woods used in electric guitars. IAWA J. 4O: 106-123. DOI: 10.1163/22941932-40190218.

Andersson S, Serimaa R, Paakkari T, Saranpää P, Pesonen E. 2003. Crystallinity of wood and the size of cellulose crystallites in Norway spruce (Picea abies). J. Wood Sci. 49:531-537. DOI:10.1007/s10o86o०3-0518-x.

Andersson S, Serimaa R, Väänänen T, Paakkari T, Jämsä S, Viitaniemi P. 2005. X-ray scattering studies of thermally modified Scots pine (Pinus sylvestris L.). Holzforschung 59: 422-427. DOI: 10.1515/ HF.2005.069.

Andersson S, Wang Y, Pönni R, Hänninen T, Mononen M, Ren H, Saranpää P. 2015. Cellulose structure and lignin distribution in normal and compression wood of the Maidenhair tree (Ginkgo biloba L.). J. Integr. Plant Biol. 57: 388-395. DOI: 10.1111/jipb.12349.

Badia MA, Constant T, Mothe F, Nepveu G. 20o6. Tension wood occurrence in three cultivars of Populus $\times$ euramericana. Part I: inter-clonal and intra-tree variability of tension wood. Ann. For. Sci. 63: 23-30. DOI: 10.1051/forest:2005095.

Brereton NJB, Ahmed F, Sykes D, Ray MJ, Shield I, Karp A, Murphy RJ. 2015. X-ray micro-computed tomography in willow reveals tissue patterning of reaction wood and delay in programmed cell death. BMC Plant Biol. 15: 83. DOI: 10.1186/s12870-015-0438-o.

Canadell JG, Raupach MR. 2008. Managing forests for climate change mitigation. Science 320: 14561457. DOI: 10.1126/science.1155458.

Chahine GA, Blanc N, Arnaud S, De Geuser F, Guinebretière R, Boudet N. 2019. Advanced nondestructive in situ characterization of metals with the French collaborating research group D2AM/BMo2 beamline at the European synchrotron radiation facility. Metals 9: 352. DOI: 10. 339o/met9o3o352.

Chang SS, Clair B, Ruelle J, Beauchêne J, Di Renzo F, Quignard F, Gril J. 20og. Mesoporosity as a new parameter for understanding tension stress generation in trees. J. Exp. Bot. 6o: 3023-3030. DOI: $10.1093 / \mathrm{jxb} / \mathrm{erp133}$.

Chang SS, Quignard F, Alméras T, Clair B. 2015. Mesoporosity changes from cambium to mature tension wood: a new step toward the understanding of maturation stress generation in trees. New Phytol. 205: 1277-1287. DOI: 10.1111/nph.13126.

Chave J, Sabatier UP. 20o6. 'Measuring wood density for tropical forest trees'. Available online at http://www.rainfor.org/upload/ManualsEnglish/wood_density_english $\% 5$ B1 $\% 5$ D.pdf.

Chow J, Doria G, Kramer R, Schneider T, Stoike J. 2013. Tropical forests under a changing climate and innovations in tropical forest management. Trop. Conserv. Sci. 6: 315-324. DOI: 10.1177/ 194008291300600302.

Clair B, Ruelle J, Beauchêne J, Prévost MF, Fournier M. 2006. Tension wood and opposite wood in 21 tropical rain forest species. IAWA J. 27: 329-338. DOI: 10.1163/22941932-900oo158.

Clair B, Déjardin A, Pilate G, Alméras T. 2018. Is the G-layer a tertiary cell wall? Front. Plant Sci. 9: 623. DOI: $10.3389 /$ fpls.2018.0o623.

de Borst K, Bader TK. 2014. Structure-function relationships in hardwood - insight from micromechanical modelling. J. Theor. Biol. 345: 78-91. DOI: 10.1016/J.JTBI.2013.12.013.

de Borst K, Bader TK, Wikete C. 2012. Microstructure-stiffness relationships of ten European and tropical hardwood species. J. Struct. Biol. 177: 532-542. DOI: 10.1016/J.JSB.2011.10.010. 
Doucet M, Cho JH, Alina G, Bakker J, Bouwman W, et al. 2017. 'SasView version 4.1'. Available online at https://zenodo.org/record/438138\#.XOKHOOgzZaQ.

Fernandes AN, Thomas LH, Altaner CM, Callow P, Forsyth VT, et al. 2011. Nanostructure of cellulose microfibrils in spruce wood. Proc. Natl. Acad. Sci. USA 108: E1195-E12O3. DOI: 10.1073/pnas. 1108942108.

Foston M, Hubbell CA, Samuel R, Jung S, Fan H, et al. 2011. Chemical, ultrastructural and supramolecular analysis of tension wood in Populus tremula $\times$ alba as a model substrate for reduced recalcitrance. Energ. Environ. Sci. 4: 4962-4971. DOI: 10.1039/C1EE02073K.

Gardiner B, Barnett J, Saranpää P, Gril J (eds.). 2014. The biology of reaction wood. Springer, New York, NY. DOI: 10.1007/978-3-642-10814-3.

Ghislain B, Clair B. 2017. Diversity in the organisation and lignification of tension wood fibre walls a review. IAWA J. 38: 245-265. DOI: 10.1163/22941932-20170170.

Hänninen T, Tukiainen P, Svedström K, Serimaa R, Saranpää P, et al. 2012. Ultrastructural evaluation of compression wood-like properties of common juniper (Juniperus communis L.). Holzforschung 66: 389-395. DOI: 10.1515/hf.2011.166.

Hashimoto T, Kawamura T, Harada M, Tanaka H. 1994. Small-angle scattering from hexagonally packed cylindrical particles with paracrystalline distortion. Macromolecules 27:3063-3072. DOI: 10.1021/maooo8gao25.

Ioelovich M, Larina E. 1999. Parameters of crystalline structure and their influence on the reactivity of cellulose I. Cell. Chem. Technol. 33: 3-12.

IUCN. 2018. IUCN red list of threatened species. Available online at https://www.iucnredlist.org/ (accessed 14 May 2019).

Jakob HF, Fengel D, Tschegg SE, Fratzl P. 1995. The elementary cellulose fibril in Picea abies: comparison of transmission electron microscopy, small-angle X-ray scattering, and wide-angle X-ray scattering results. Macromolecules 28: 8782-8787. DOI: 10.1021/maoo13oao1o.

Jakob HF, Tschegg SE, Fratzl P. 1996. Hydration dependence of the wood-cell wall structure in Picea abies. A small-angle X-ray scattering study. Macromolecules 29: 8435-8440. DOI: 10.1021/ MA9605661.

Jarvis MC. 2018. Structure of native cellulose microfibrils, the starting point for nanocellulose manufacture. Philos. Trans. Roy. Soc. A 376: 20170045. DOI: 10.1098/rsta.2017.0045.

Leppänen K, Andersson S, Torkkeli M, Knaapila M, Kotelnikova N, Serimaa R. 20og. Structure of cellulose and microcrystalline cellulose from various wood species, cotton and flax studied by X-ray scattering. Cellulose 16: 999-1015. DOI: 10.1007/s10570-0o9-9298-9.

Leppänen K, Bjurhager I, Peura M, Kallonen A, Suuronen JP, et al. 2011. X-ray scattering and microtomography study on the structural changes of never-dried silver birch, European aspen and hybrid aspen during drying. Holzforschung 65: 865-873. DOI: 10.1515/HF.2011.108.

Meier EW. 2015. Identifying and using hundreds of woods worldwide. Wood Database.

Müller M, Burghammer M, Sugiyama J. 2006. Direct investigation of the structural properties of tension wood cellulose microfibrils using microbeam X-ray fibre diffraction. Holzforschung 6o: 474-479. DOI: 10.1515/HF.2006.078.

Newman RH, Hill SJ, Harris PJ. 2013. Wide-angle X-ray scattering and solid-state nuclear magnetic resonance data combined to test models for cellulose microfibrils in mung bean cell walls. Plant Physiol. 163: 1558-1567. DOI: 10.1104/pp.113.228262.

Penttilä PA, Rautkari L, Österberg M, Schweins R. 2019. Small-angle scattering model for efficient characterization of wood nanostructure and moisture behavior. J. Appl. Crystallogr. 52: 369-377. DOI: 10.1107/S16oo576719002012.

Penttilä PA, Altgen M, Carl N, van der Linden P, Morfin I, et al. 2020. Moisture-related changes in the nanostructure of woods studied with X-ray and neutron scattering. Cellulose 27: 71-87. DOI: 10. 1007/s10570-019-02781-7. 
Roussel J-R, Clair B. 2015. Evidence of the late lignification of the G-layer in Simarouba tension wood, to assist understanding how non-G-layer species produce tensile stress. Tree Physiol. 35: 13661377. DOI: 10.1093/treephys/tpvo82.

Ruelle J, Clair B, Beauchêne J, Prévost MF, Fournier M. 20o6. Tension wood and opposite wood in 21 tropical rain forest species. IAWA J. 27: 341-376. DOI: 10.1163/22941932-90ooo159.

Ruelle J, Yamamoto H, Thibaut B. 2007. Growth stresses and cellulose structural parameters in tension and normal wood from three tropical rainforest angiosperm species. BioResources. 2: 235-251. DOI: 10.15376/biores.2.2.235-251.

Sarén MP, Serimaa R, Andersson S, Saranpää P, Keckes J, Fratzl P. 2004. Effect of growth rate on mean microfibril angle and cross-sectional shape of tracheids of Norway spruce. Trees 18: $354-362$. DOI: 10.1007/soo468-003-0313-8.

Sawada D, Kalluri UC, O'Neill H, Urban V, Langan P, Davison B, Pingali SV. 2018. Tension wood structure and morphology conducive for better enzymatic digestion. Biotechnol. Biofuels 11: 44. DOI: 10.1186/s13068-018-1043-x.

Shearman P, Bryan J, Laurance WF. 2012. Are we approaching 'peak timber' in the tropics? Biol. Conserv. 151: 17-21. DOI: 10.1016/J.BIOCON.2011.10.036.

Tazaki K, Fukuyama A, Tazaki F, Takehara T, Nakamura K, et al. 2017. Electron microscopy observation of biomineralization within wood tissues of Kurogaki. Minerals 7: 123. DOI: 10.339o/min7070123.

Thomas LH, Forsyth VT, Martel A, Grillo I, Altaner CM, Jarvis MC. 2014. Structure and spacing of cellulose microfibrils in woody cell walls of dicots. Cellulose 21: $3887-3895$. DOI: $10.1007 /$ s1057O-014o431-z.

Wang Y, Leppänen K, Andersson S, Serimaa R, Ren H, Fei B. 2012. Studies on the nanostructure of the cell wall of bamboo using X-ray scattering. Wood Sci. Technol. 46: 317-332. DOI: 10.1007/soo226o11-0405-3.

Edited by Lloyd Donaldson 


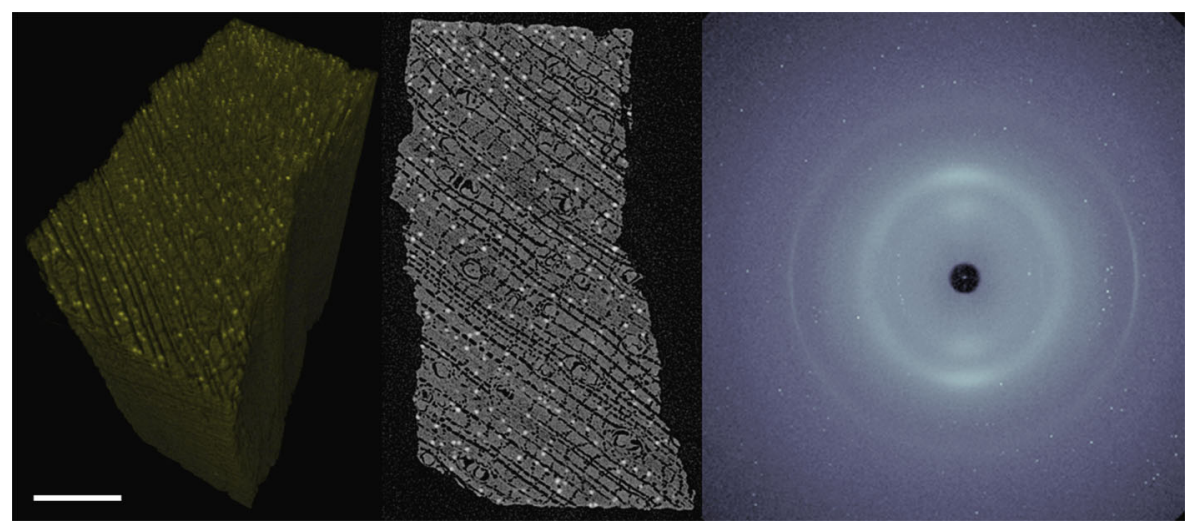

Figure A1. Left: A microtomography $(\mu \mathrm{CT})$ images of ebony ( $5 \mu \mathrm{m}$ voxel size) clearly showing the deposits of crystalline compounds. Right: The WAXS scattering image of ebony B (Diospyros crassiflora) where the crystalline compounds of wood extractives are shown as bright spots. The length of the scale bar is $1 \mathrm{~mm}$.
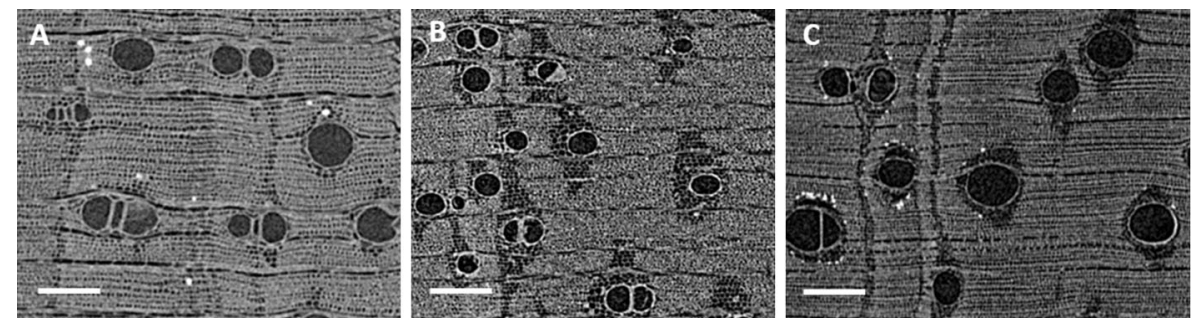

Figure A2. Single slices of $\mu$ CT from selected tropical wood species. (A) Bubinga, (B) purpleheart and (C) zebrawood imaged with $5 \mu \mathrm{m}$ voxel size. The length of the scale bar in every image is $200 \mu \mathrm{m}$. 


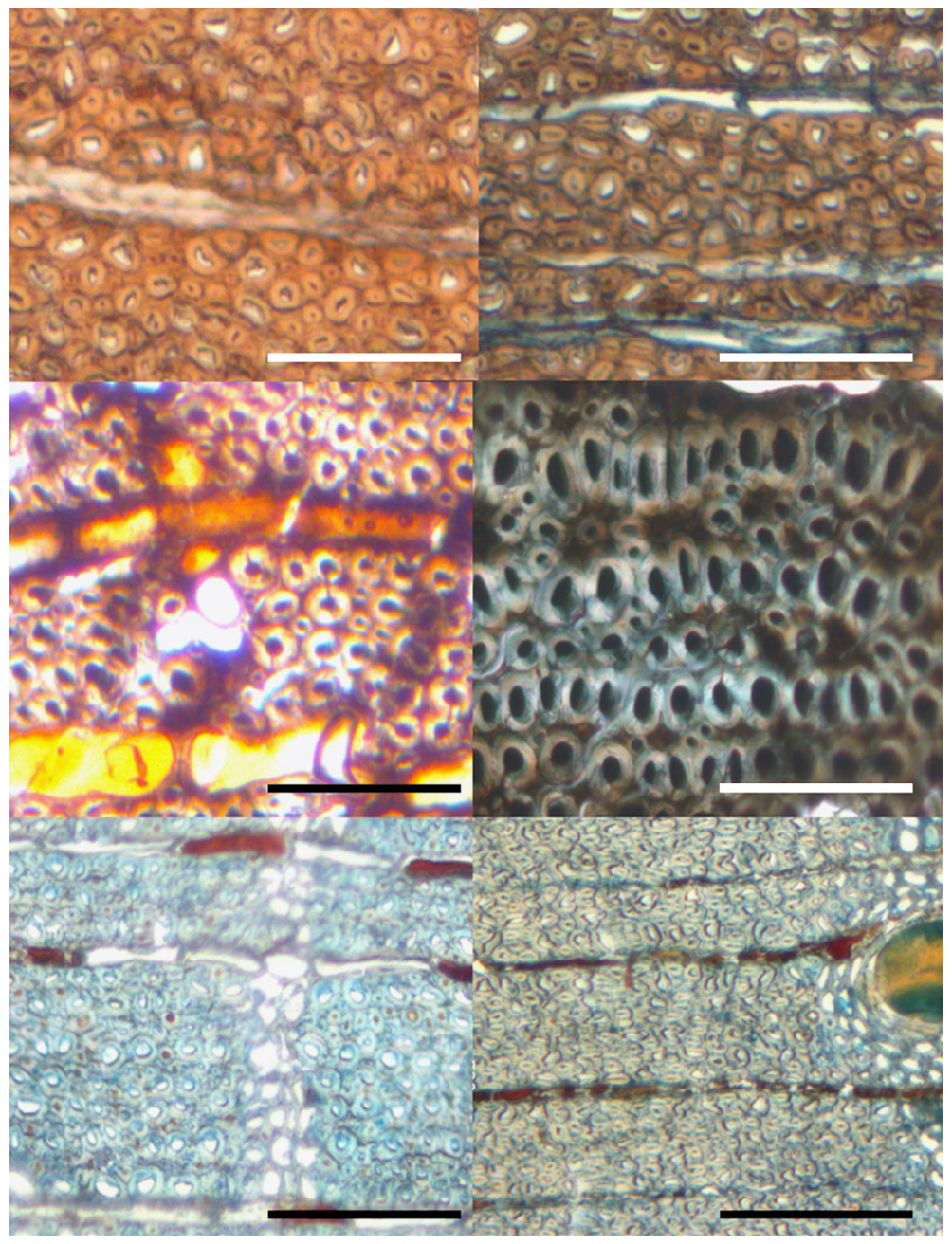

Figure A3. Light microscopy and staining results. Up-left: rosewood A (TW) non-stained vs right: rosewood A (TW) stained. Middle-left: ebony A (NW) non-stained vs right: ebony A (NW) stained. Down-left: msasa B (NW) stained vs. right: msasa A (TW) stained. The length of the scale bar is in every image $100 \mu \mathrm{m}$. 